\title{
Sex-specific trends in lung cancer incidence and survival: a population study of 40118 cases
}

\author{
Camilla M T Sagerup, ${ }^{1}$ Milada Småstuen, ${ }^{2}$ Tom B Johannesen, ${ }^{2}$ Åslaug Helland, ${ }^{1}$ \\ Odd Terje Brustugun ${ }^{1}$
}

${ }^{1}$ University of Oslo, Institute of Clinical Medicine, Oslo, Norway ${ }^{2}$ Cancer Registry of Norway, Institute of Population-Based Cancer Research, Norway

\section{Correspondence to}

Camilla M T Sagerup, Department of Genetics, Institute for Cancer Research, Oslo University Hospital Radiumhospitalet, Montebello, 0310 Oslo, Norway; camilla.sagerup@rr-research.no

Received 22 September 2010 Accepted 28 November 2010 Published Online First 2 January 2011

\section{ABSTRACT}

Background and aim Lung cancer is increasingly affecting women. The aim of this study was to identify sex-specific trends in lung cancer incidence and survival. Methods Complete national data on 40118 cases from the Cancer Registry of Norway sampled from 1988 to 2007 are presented, with incidence rates, 1- and 5-year relative survival in 5 year intervals and multivariate HRs adjusted for covariates, each with 95\% Cls.

Results Lung cancer incidence increased by $64 \%$, with an age-adjusted annual average increase of $4.9 \%$ in women and $1.4 \%$ in men in this period. Relative survival was lower in men than in women in all time periods, and men had an increased risk of dying within 5 years of diagnosis compared with women (HR 1.14, 95\% Cl 1.11 to 1.17), adjusted for covariates. Adenocarcinoma is now the most frequent histological group in men and women, yet the risk of dying was higher in men in all histological subtypes except squamous cell carcinoma. A higher proportion of women than men were diagnosed with localised disease, and the risk of dying was significantly higher in men among all stages, most apparent in localised disease (HR 1.25, 95\% Cl 1.18 to 1.33).

Conclusion The findings highlight important characteristics of the lung cancer epidemic; despite a rising incidence of female lung cancer cases, women are diagnosed with less advanced disease than men; when adjusted for covariates, men have an increased risk of excess death at 5 years compared with women, irrespective of stage, age, period of diagnosis and selected histological subgroups.

\section{INTRODUCTION}

Lung cancer retains its status as the most common cancer in the world, with an estimated 1.5 million cases diagnosed in 2007 , accounting for $\sim 12 \%$ of all cancers. ${ }^{1}$ With a rising incidence in women, there is an increased focus on sex-specific differences in lung cancer. ${ }^{2-4} \mathrm{~A}$ higher proportion of women than men are diagnosed with adenocarcinoma, ${ }^{5}$ and women are also more likely to be younger and diagnosed at an earlier stage of disease. 6 Large cooperative group databases have previously been analysed regarding the independent contribution of female sex to lung cancer outcome, yet many studies were conducted before the introduction of concurrent chemoradiotherapy and third-generation regimens that have had a favourable impact on survival.

A number of smaller studies examining sex differences in lung cancer survival have recently emerged. ${ }^{4}$ However, many are limited by selection bias attributed to clinical trials, including only patients who underwent chemotherapy ${ }^{8} 9$ or surgery. ${ }^{10-12}$ Patients with advanced disease and of older age are therefore often excluded from such analyses. As females still comprise a smaller number of lung cancer patients than men, sex distribution can also be skewed. ${ }^{3}$ In addition, confounding of results may have occurred in some studies due to the lack of adjustment for sex-related differences in deaths from other causes.

This study therefore aimed to examine sex-specific trends in incidence and survival in an unselected population of patients with lung cancer from a complete, national database of 40118 lung cancer cases collected in the 20 year period 1988-2007.

\section{MATERIALS AND METHODS Population demographics}

Norway has a universal, public health service financed by taxation and a national insurance scheme equally accessible to all residents, independent of social status. In the period studied, the proportion of citizens of non-western origin fluctuated from $1.3 \%$ to $4.9 \%$. In our data set, therefore, no subset analysis was conducted based on race, socioeconomic status or geography.

\section{Data collection}

Since 1952 it has been mandatory by law to report all malignant neoplasms to the Cancer Registry of Norway (CRN). In addition, copies of cytology, biopsy and autopsy reports are submitted from pathology laboratories as well as death certificate reports from the Cause of Death Register run by the National Statistics Bureau, Statistics Norway. Since 1993 all hospitals have filed discharge summaries electronically to the registry. The system of reporting to the CRN was evaluated in 2009 , and overall completeness of reporting was estimated at $98.8 \%{ }^{13}$

We collected data from 1988 onwards, since, after that time point, CT was in widespread use, implying that diagnosis and staging should be uniform throughout the country.

From the 40118 cases originally diagnosed with lung cancer, cases notified to the cancer registry by death certificate only $(n=743)$ or who were diagnosed postmortem $(n=386)$ were excluded from the survival analyses as survival time for these cases would effectively be zero.

\section{Diagnosis and staging}

The CRN utilises a condensed staging system for lung cancer reporting, based on the TNM 
Table 1 Patient characteristics stratified by successive 5-year and 20-year (1988-2007) diagnostic periods and sex

\begin{tabular}{|c|c|c|c|c|c|c|c|c|c|c|}
\hline & \multicolumn{2}{|l|}{ 1988-1992 } & \multicolumn{2}{|l|}{$1993-1997$} & \multicolumn{2}{|l|}{ 1998-2002 } & \multicolumn{2}{|l|}{ 2003-2007 } & \multicolumn{2}{|c|}{ Total (1988-2007) } \\
\hline & $\mathbf{M}$ & $F$ & M & $\mathbf{F}$ & M & $\mathbf{F}$ & M & $\mathbf{F}$ & $\bar{M}$ & $\mathbf{F}$ \\
\hline №. (\%) & $5868(71.2)$ & $2377(28.8)$ & $6360(67.4)$ & $3075(33.6)$ & $6555(63.4)$ & $3787(36.6)$ & $7196(59.5)$ & $4900(40.5)$ & $25979(65)$ & $14139(35)$ \\
\hline Adenocarcinoma & $1202(20)$ & $691(29)$ & $1404(22)$ & $919(30)$ & $1624(25)$ & $1184(31)$ & $1919(27)$ & $1632(33)$ & $6149(24)$ & $4426(31)$ \\
\hline Squamous cell carcinoma & $1937(33)$ & $418(18)$ & $1887(30)$ & $479(16)$ & $1662(25)$ & 550 (15) & $1708(24)$ & $722(15)$ & $7194(28)$ & $2169(15)$ \\
\hline Large cell carcinoma & $294(5)$ & $125(5)$ & $326(5)$ & $148(5)$ & $321(5)$ & $204(5)$ & $279(4)$ & $166(3)$ & $1220(5)$ & $643(5)$ \\
\hline Sarcoma/carcinoid tumor & $41(1)$ & $50(2)$ & $67(1)$ & $70(2)$ & $123(2)$ & $116(3)$ & $162(2)$ & $158(3)$ & $393(2)$ & $394(3)$ \\
\hline \multicolumn{11}{|l|}{ Stage } \\
\hline Localised disease & $2326(40)$ & $876(37)$ & 2407 (38) & $1176(38)$ & $1878(29)$ & $1081(29)$ & $1772(25)$ & $1337(27)$ & $8383(32)$ & $4470(32)$ \\
\hline Regional disease & $1127(19)$ & $468(20)$ & $1384(22)$ & $622(20)$ & $1624(25)$ & $871(23)$ & $2107(29)$ & $1281(26)$ & $6242(24)$ & $3242(23)$ \\
\hline Metastatic disease & $2323(40)$ & $999(42)$ & $2476(39)$ & $1230(40)$ & $2991(46)$ & $1805(48)$ & $3256(45)$ & $2231(46)$ & $11046(43)$ & $6265(44)$ \\
\hline Unknown & $92(1)$ & $34(1)$ & $93(1)$ & $47(2)$ & $62(1)$ & $30(1)$ & $61(1)$ & $51(1)$ & $308(1)$ & $162(1)$ \\
\hline $70-79$ & $2211(38)$ & $748(31)$ & $2429(38)$ & $1017(33)$ & 2558 (39) & $1271(34)$ & $2538(35)$ & $1621(33)$ & $9736(37)$ & 4657 (33) \\
\hline 80 and over & $604(10)$ & $288(12)$ & $815(13)$ & $354(12)$ & $996(15)$ & $495(13)$ & $1375(19)$ & $794(16)$ & $3790(15)$ & $1931(14)$ \\
\hline
\end{tabular}

NOS, not otherwise specifed.

classification system, in that T1-2N0M0 is 'Localised' (stage I), M1 is 'Metastatic' (stage IV) and the others are 'Regionally advanced' (stages II and III). Tumour localisation from 1992 was coded according to International Classification of Diseases, 7 th revision (ICD-7), and tumour histology was coded according to the Manual of Tumor Nomenclature and Coding. ${ }^{13}$ Since 1993, both topography and morphology have been coded according to ICD-O (International Classification of Diseases for Oncology). ${ }^{14}$

\section{Patient follow-up}

Mortality updates are conducted routinely by the CRN through linkage with the Cause of Death Register. In survival analyses, the primary outcome was survival following a diagnosis of lung cancer. Follow-up was defined as the time from lung cancer diagnosis to death as reported from the Cause of Death Register or to the last date of data submission for patients who were still alive, whichever came first.

\section{Statistical methods}

We used the CRN database December 2008 submission to analyse male and female survival and incidence rates from 1988 to 2007. In addition to sex and histological type, we evaluated demographic characteristics including age at diagnosis and stage. We divided the study period into calendar years. Temporal trends were expressed as the percentage change $=(100 \times($ final incidence rate-initial incidence rate)/initial incidence rate. Incidence data are presented as age adjusted by the direct method to the standard world population. ${ }^{16}$

We calculated 1- and 5-year male and female relative survival (RS) stratified by age, stage and histological type for individuals diagnosed through successive 5 year calendar periods. We estimated RS for men and women using the method of Hakulinen, ${ }^{17}$ where the survival time of the matched individual is censored at the same survival time as that of the patient with cancer. RS adjusts for competing causes of death expected for persons of the same sex, age and calendar year of investigation (the ratio of observed survival in a population to the expected survival rate); hence cause of death information is not required.

A Cox proportional hazards model was fitted to estimate the $\mathrm{RR}$ of death for males versus females and adjusted for covariates possibly associated with survival: histology, stage, age and diagnostic period. In addition, the effect of sex on postdiagnosis survival was assessed by estimating relative risks of death for men versus women stratified by stage, histology, age groups and diagnostic periods. $p$ Values $<0.05$ were considered statistically

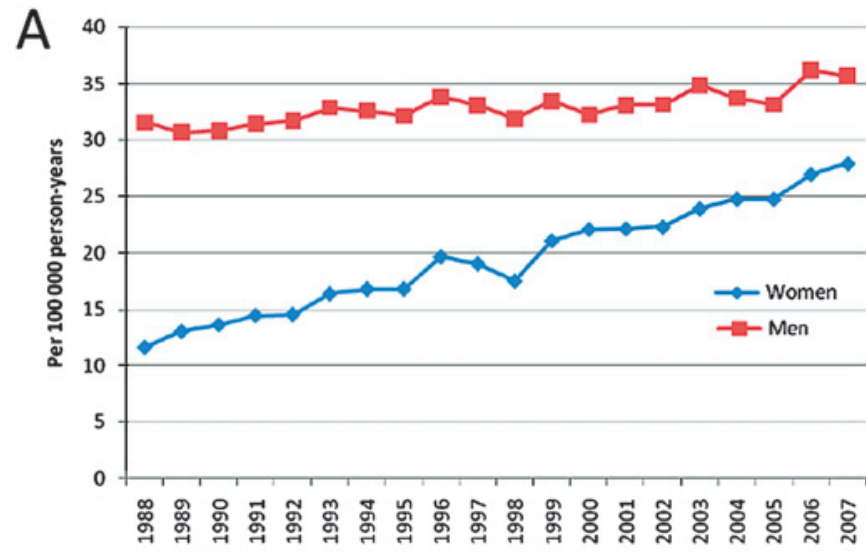

B

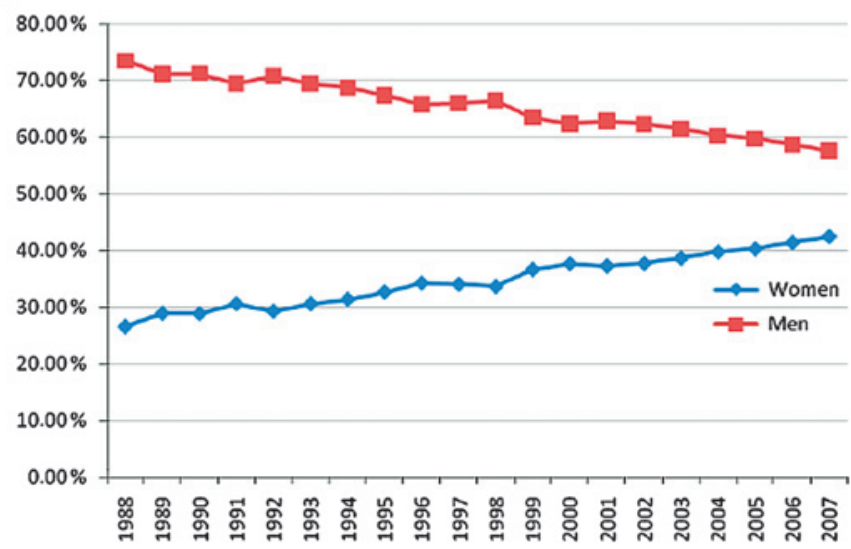

Figure 1 (A) Age-adjusted lung cancer incidence rates by sex. (B) Sex-specific incidence fraction. 
1-year relative survival

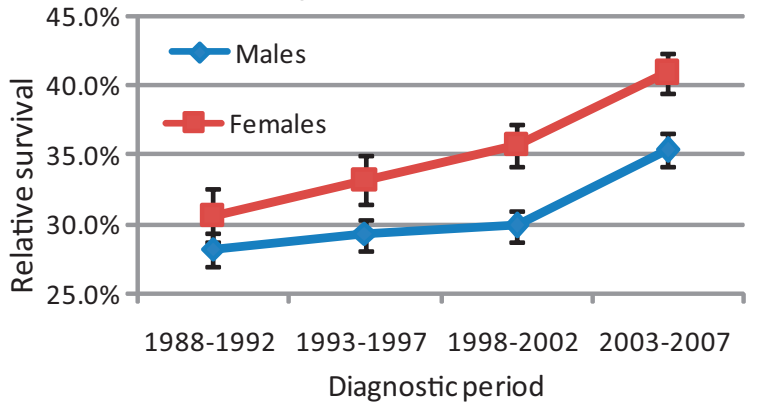

5-year relative survival

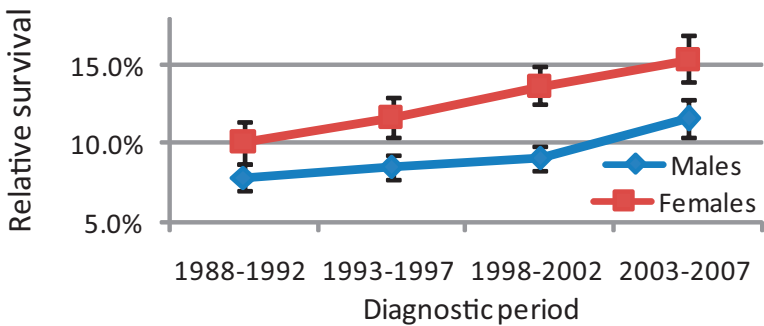

1-year relative survival $(95 \% \mathrm{Cl})$

Males

$28.2(27-29.4)$
$29.3(28.1-30.4)$
$29.9(28.7-31)$
$35.3(34.2-36.5)$

30.6 (28.7-32.5)

33.2 (31.5-35)

35.7 (34.1-37.2)

$40.9(39.5-42.4)$
5 -year relative survival $(95 \% \mathrm{Cl})$

Males

$7.9(7.1-8.7)$

8.6(7.8-9.4)

9.1(8.3-9.9)

11.6(10.5-12.8) 5-year relative surviva $(95 \% \mathrm{Cl})$

\section{Females}

1998-2002

Figure 2 One- and 5-year relative survival by sex and diagnostic period.

significant. All analyses were performed using Stata version 11 and SPSS version 17.

\section{RESULTS}

\section{Patient characteristics}

A total of 40118 cases were included in the study; 14139 (35\%) were women and 25979 (65\%) were men. Clinicopathological characteristics are reported in table 1.

\section{Incidence and survival by sex}

By 2007, the age-adjusted lung cancer incidence was 36 per 100000 person years for men and 28 per 100000 person years for women (figure 1A). In 1988 the ratio of men to women with the disease was nearly 3:1, whereas in 2007 the ratio was close to $3: 2$ (figure $1 \mathrm{~B}$ ). This corresponds to an average age-adjusted annual increase of $4.9 \%$ in women, and $1.4 \%$ in men (1988-2007).

One- and 5-year RS from lung cancer increased over time in both sexes, with greater improvement seen in 5 year RS, from $7.9 \%$ and $10.1 \%$ in $1988-92$, to $11.6 \%$ and $15.4 \%$ in $2003-07$ for men and women, respectively. In all 5 year diagnostic periods, survival was lower in men than in women (figure 2). For the whole period, men exhibited a $14 \%$ increased risk of dying $(95 \%$ CI 1.11 to 1.17) within 5 years of diagnosis compared with women, when adjusted for covariates (figure $3 \mathrm{~A}$ and table 2). When stratified by diagnostic periods, the risk ratios were not significantly different over time (table 3 ).
A

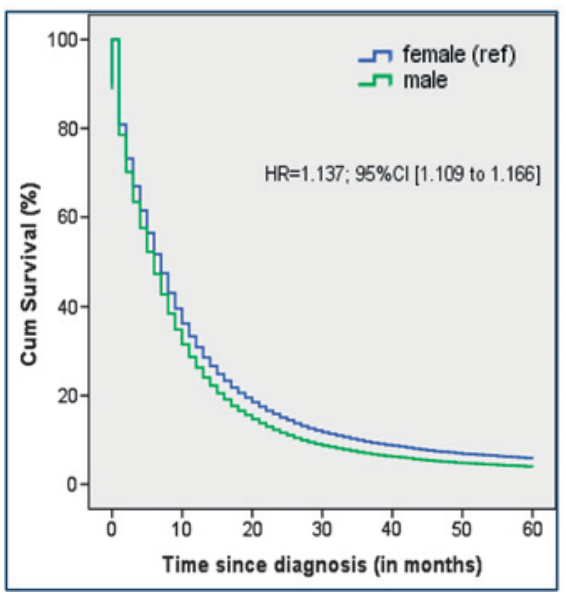

B

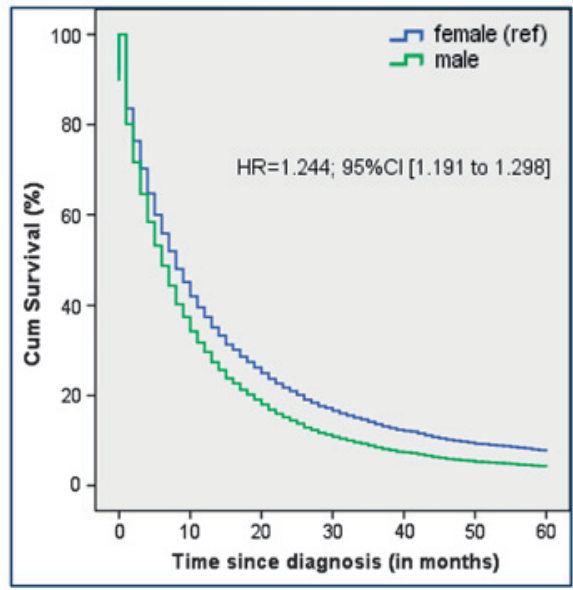

C

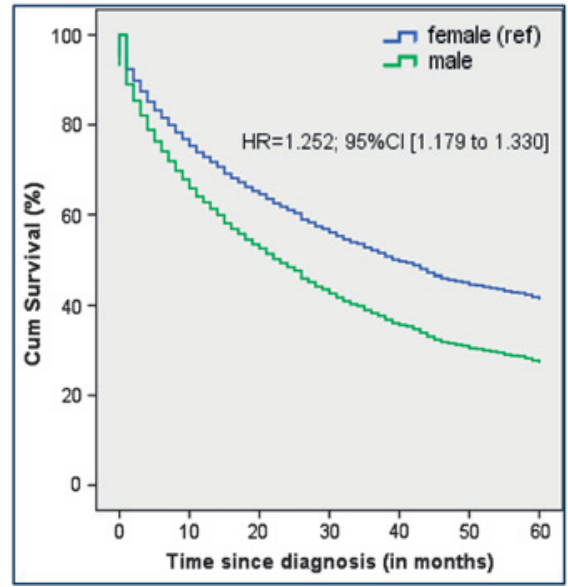

Figure 3 (A) Survival stratified by sex and adjusted for histology, stage, age and diagnostic period. (B) Survival of patients with adenocarcinoma stratified by sex and adjusted for stage, age and diagnostic period. (C) Survival of patients with localised disease stratified by sex and adjusted for histology, age and diagnostic period. 
Table 2 Cox proportional hazards model fitted to estimate the RR of death for males versus females and adjusted for the covariates histology, stage, age and diagnostic period

\begin{tabular}{|c|c|c|}
\hline & HR $(95 \% \mathrm{Cl})$ & p Value \\
\hline \multicolumn{3}{|l|}{ Sex } \\
\hline \multicolumn{3}{|c|}{ (adjusted for histology, stage, age and diagnostic period) } \\
\hline \multicolumn{3}{|c|}{ Female* } \\
\hline Male & 1.137 (1.109 to 1.166$)$ & $<0.001$ \\
\hline \multicolumn{3}{|l|}{ Histology } \\
\hline \multicolumn{3}{|c|}{ (adjusted for stage, age and diagnostic period) } \\
\hline \multicolumn{3}{|c|}{ Adenocarcinoma* } \\
\hline NOS & $1.198(1.156$ to 1.241$)$ & $<0.001$ \\
\hline Squamous cell carcinoma & 0.976 (945 to 1.009 ) & 0.150 \\
\hline Small cell carcinoma & $1.170(1.132$ to 1.210$)$ & $<0.001$ \\
\hline Large cell carcinoma & $1.122(1.062$ to 1.185$)$ & $<0.001$ \\
\hline \multicolumn{3}{|l|}{ Stage } \\
\hline \multicolumn{3}{|c|}{ (adjusted for histology, age and diagnostic period) } \\
\hline \multicolumn{3}{|c|}{ Localised disease $^{*}$} \\
\hline Regional disease & 1.539 (1.486 to 1.594$)$ & $<0.001$ \\
\hline Metastatic disease & 3.367 (3.257 to 3.481$)$ & $<0.001$ \\
\hline \multicolumn{3}{|l|}{ Age (years) } \\
\hline \multicolumn{3}{|c|}{ (adjusted for histology, stage and diagnostic period) } \\
\hline \multicolumn{3}{|c|}{$0-49^{*}$} \\
\hline $50-59$ & $1.103(1.039$ to 1.171$)$ & 0.001 \\
\hline $60-69$ & $1.274(1.204$ to 1.347$)$ & $<0.001$ \\
\hline $70-79$ & $1.661(1.570$ to 1.756$)$ & $<0.001$ \\
\hline 80 and over & 2.508 (2.354 to 2.673 ) & $<0.001$ \\
\hline \multicolumn{3}{|l|}{ Diagnostic period } \\
\hline \multicolumn{3}{|c|}{ (adjusted for histology, stage and age) } \\
\hline \multicolumn{3}{|c|}{$1988-1992^{*}$} \\
\hline 1993-1997 & $0.954(0.922$ to 0.987$)$ & 0.007 \\
\hline 1998-2002 & $0.831(0.804$ to 0.860$)$ & $<0.001$ \\
\hline $2003-2007$ & $0.714(0.690$ to 0.738$)$ & $<0.001$ \\
\hline
\end{tabular}

*Reference group.

NOS, not otherwise specifed

\section{Histology}

The distribution of histological subtypes has shifted within the 20 year period studied. In 1988 squamous cell carcinoma comprised the largest subgroup of lung cancer among men (38\%), yet in 2007 it accounted for only $22 \%$ of cases (figure $4 \mathrm{~A}$ ). In women, adenocarcinoma was the most frequent histological subtype throughout the period studied (figure 4B).

Notably, long-term survival improved significantly over time in patients with squamous cell carcinoma and women with adenocarcinoma. Five-year RS was lowest in patients diagnosed with small cell lung caner (SCLC), with no significant survival improvement over time seen in either sex (table 4). When adjusted for covariates, men had a significantly increased risk of dying within 5 years of diagnosis for all histological subtypes except squamous cell carcinoma. Men with adenocarcinoma had a $24 \%$ higher risk of dying (95\% CI 1.19 to 1.30 ) than women (figure $3 \mathrm{~B}$ and table 3 ).

\section{Stage and age}

Within the period 1993-2004, a decrease in the proportion of patients presenting with localised disease at the time of diagnosis was observed in both sexes among all entities, comprising 44\% of all cases in 1993 and only 22\% in 2004 (data not shown). Men were older than women at the time of diagnosis. In 1988-92 the median age was 68 years in women versus 69 years in men. By the last 5 years studied, median age had increased by 1 year in women and 2 years in men (data not shown).

A significant improvement in 5-year RS over time was evident in patients with localised disease, yet no significant improvement
Table 3 Relative risks of death within 5 years of diagnosis for men versus women stratified by histology, stage, age groups and diagnostic periods

\begin{tabular}{|c|c|}
\hline $\begin{array}{l}\text { Females } \\
(\mathrm{n}=13983) \\
\mathrm{HR} 95 \% \mathrm{Cl}\end{array}$ & $\begin{array}{l}\text { Males } \\
(\mathrm{n}=25 \mathrm{721}) \\
\text { HR } 95 \% \mathrm{Cl}\end{array}$ \\
\hline
\end{tabular}

Histology

(adjusted for stage, age and diagnostic period)

$\begin{array}{llll}\text { Adenocarcinoma } & 1.000 & 1.244(1.191 \text { to } 1.298) & <0.001 \\ \text { NOS } & 1.000 & 1.141(1.078 \text { to } 1.207) & <0.001 \\ \text { Squamous cell carcinoma } & 1.000 & 1.048(0.994 \text { to } 1.105) & 0.084 \\ \text { Small cell carcinoma } & 1.000 & 1.052(1.001 \text { to } 1.105) & 0.045 \\ \text { Large cell carcinoma } & 1.000 & 1.147(1.033 \text { to } 1.273) & 0.010\end{array}$

Stage

(adjusted for histology, age and diagnostic period)

$\begin{array}{llll}\text { Localised disease } & 1.000 & 1.252(1.179 \text { to } 1.330) & <0.001 \\ \text { Regional disease } & 1.000 & 1.112(1.059 \text { to } 1.168) & <0.001 \\ \text { Metastatic disease } & 1.000 & 1.103(1.066 \text { to } 1.141) & <0.001 \\ \text { Unknown } & 1.000 & 1.135(1.045 \text { to } 1.233) & 0.003\end{array}$

Age (years)

(adjusted for histology, stage and diagnostic period)

$\begin{array}{lllr}0-49 & 1.000 & 1.169(1.053 \text { to } 1.298) & 0.003 \\ 50-59 & 1.000 & 1.185(1.117 \text { to } 1.257) & <0.001 \\ 60-69 & 1.000 & 1.169(1.119 \text { to } 1.220) & <0.001 \\ 70-79 & 1.000 & 1.108(1.064 \text { to } 1.154) & <0.001 \\ 80 \text { and over } & 1.000 & 1.095(1.017 \text { to } 1.179) & 0.016\end{array}$

Diagnostic period

(adjusted for histology, stage and age)

\begin{tabular}{lrlr}
$1988-1992$ & 1.000 & $1.100(1.042$ to 1.162$)$ & 0.001 \\
$1993-1997$ & 1.000 & $1.137(1.081$ to 1.196$)$ & $<0.001$ \\
$1998-2002$ & 1.000 & $1.163(1.110$ to 1.218$)$ & $<0.001$ \\
$2003-2007$ & 1.000 & $1.125(1.076$ to 1.175$)$ & $<0.001$ \\
\hline
\end{tabular}

NOS, not otherwise specifed.

in long-term survival was seen among patients with regional or metastatic disease (table 4). The risk of dying within 5 years of diagnosis, after adjusting for covariates, was significantly higher in men than in women among all stages (table 3). A sex difference was most evident in patients with localised disease, where men had a $25 \%$ (95\% CI 1.18 to 1.33 ) increased risk of dying compared with women (figure $3 \mathrm{C}$ and table 3 ). Adjusting for covariates, women also had a significant survival advantage over men irrespective of age groups (table 3 ).

\section{DISCUSSION}

In this large, national population-based study with complete data from >40000 lung cancer cases collected from 1988 to 2007, we performed a detailed, sex-specific analysis of incidence and survival trends. We confirmed a trend of rising lung cancer incidence among females. Adenocarcinomas now comprise the largest entity in both sexes, and a higher proportion of women are diagnosed at an earlier stage and age than men. Short- and long-term survival has increased in both sexes, and through multivariate analysis we show that male sex is an unfavourable prognostic factor for lung cancer survival irrespective of age, stage, diagnostic period and, to a certain extent, histology. To our knowledge, this is the largest study to date to examine sex-related differences in lung cancer incidence and survival where an unselected population of patients with lung cancer is represented.

\section{Incidence and survival trends}

In many developed nations, incidence rates have been observed to decline, although rates vary by histological subtypes. ${ }^{18} 19$ 
A
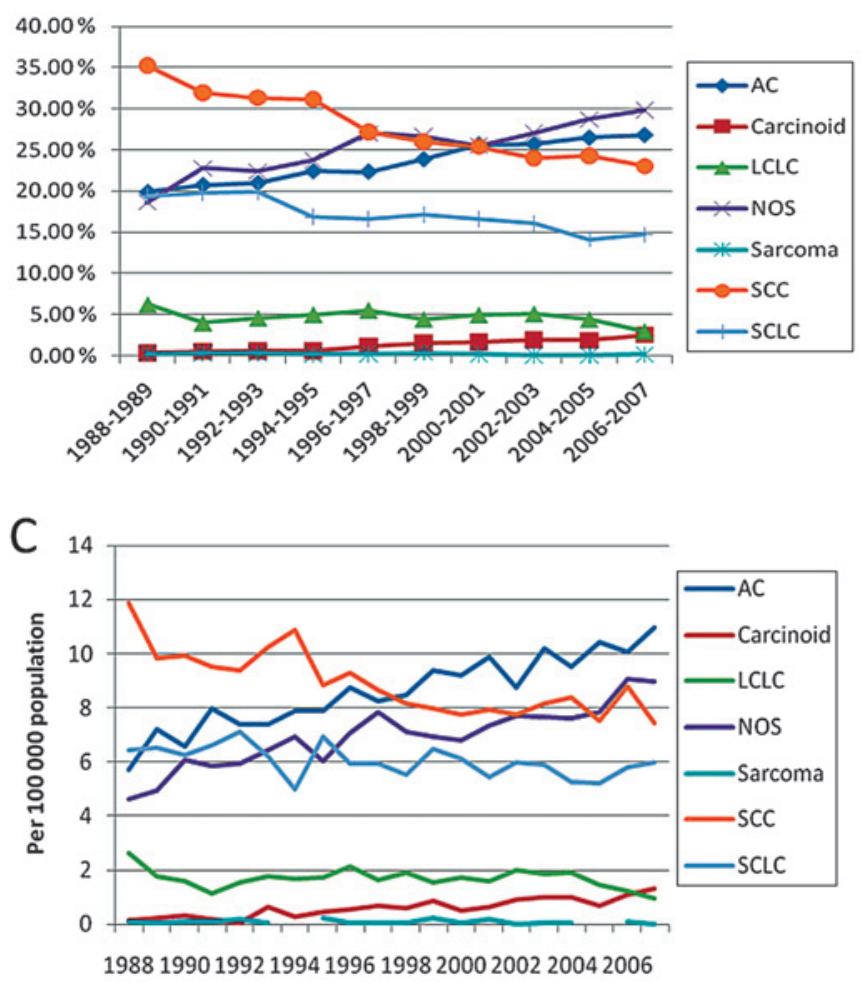

B
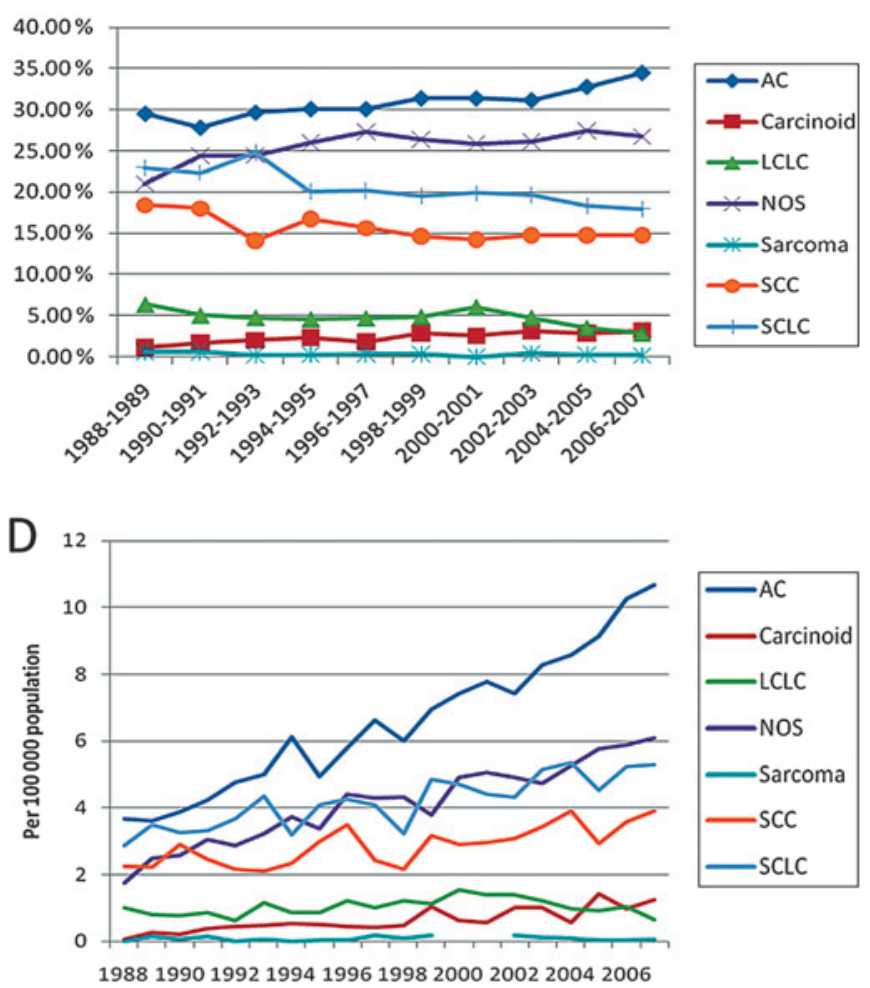

Figure 4 (A) Male lung cancer incidence proportion of histological subgroups. (B) Female lung cancer incidence proportion of histological subgroups. (C) Age-adjusted lung cancer incidence rates in men stratified by histological subgroups. (D) Age-adjusted lung cancer incidence rates in women stratified by histological subgroups.

Observed variations in incidence rates by sex have been correlated with smoking history. The case is still far from settled concerning dose correlation and differences in risk ratios by sex. $^{2} 20$ In the CRN individual smoking history is not collected and a direct correlation with lung cancer incidence cannot be made. However, the number of smokers is declining in both sexes, albeit at a slower rate in women. In 2007, 23\% of Norwegian women were smokers versus $21 \%$ of all men. ${ }^{21}$ The current rate of increase in lung cancer incidence in Norwegian women will most probably abate in the near future, as already observed in other developed countries. ${ }^{19}$

One- and 5-year survival increased in both sexes. Among Nordic countries, where it is natural to compare survival due to similar population demographics, cancer registries and access to and quality of healthcare, sex-specific survival is still comparatively lower in Norway than in its neighbouring country Sweden. ${ }^{22}$ A historical delay and underuse of thirdgeneration chemotherapy might play a role in this observed difference. A standardised, national treatment protocol for lung cancer was first implemented in 2000, and introduction of thirdgeneration chemotherapy in 1998 in Norway increased 1-year survival by $4 \%$ in patients with advanced stage disease. ${ }^{23}$ Varying exposure within countries to other risk factors that affect co-morbidity, such as tobacco and alcohol, is perhaps less likely to affect survival in a disease that itself has such a severe prognosis.

\section{Histology}

In line with other reports, ${ }^{18}$ we found an increase in the incidence of adenocarcinoma in both men and women, now the most prevalent histological subgroup in both sexes. In women,
SCLC and, to a lesser extent, squamous cell carcinoma incidence rates also increased. In lung cancer, these histological entities display the strongest overall relationship between intensity and duration of smoking. ${ }^{3} 2425$ In women, smoking intensity (consumption of tobacco) increased until 1990 and is now only slightly below consumption in men. In addition, smoking in older birth cohorts in women was rare up to the 1970s. ${ }^{21}$ Hence, consumption as well as duration of smoking have increased over time, factors that might play a role in histology-specific incidence rates.

Our study indicates that women have a survival advantage within all histological subsets except squamous cell carcinoma. In accordance with previous studies, ${ }^{41126}$ a survival advantage among women was most pronounced in patients diagnosed with adenocarcinoma. We must take into account that other factors not included in our multivariable model could influence the results. It has been postulated that sex impact on survival rates is due to a difference in smoking status between men and women. Several studies have shown that a larger proportion of women than men among patients with adenocarcinoma are never-smokers, ${ }^{27}$ and never-smokers with lung cancer respond better to treatment ${ }^{28}$ and live longer ${ }^{27}$ compared with current smokers. However, smoking status as a prognostic factor is not necessarily limited by histological subtype. ${ }^{29}$ We cannot exclude, as some studies might indicate, that female sex is only a surrogate for other prognostic markers. A Japanese study that analysed the impact of epidermal growth factor receptor (EGFR) mutation status according to sex and smoking status on survival found EGFR mutations to be more prevalent in women, although among never-smokers the prevalence was similar between the sexes. ${ }^{30}$ 


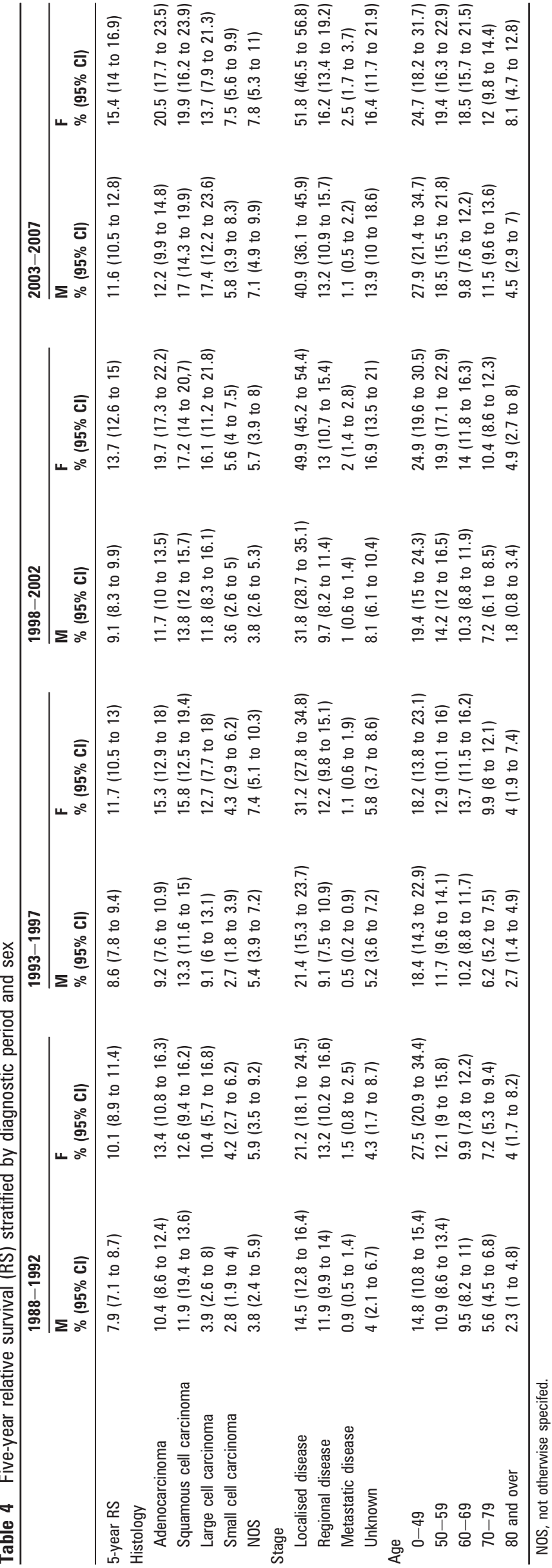

As shown elsewhere, short-term survival of SCLC has improved since the introduction of chemotherapy in the 1970s. ${ }^{31}$ However, no significant improvement in RS in either sex in the period 1988-2007 was evident in our material. Despite the poor overall survival of patients diagnosed with SCLC, men appear to have an increased risk of dying also when adjusting for confounders compared with women. Due to the low proportion of women with SCLC (15-20\%), only large trials allow statistical evaluation of sex as a prognostic variable. Osterlind et al found sex to be a prognostic factor in patients with SCLC with limited disease ${ }^{32}$ and, in a retrospective study by Johnson et al that encompassed the period 1973-1986, women survived significantly longer than men when adjusted for other significant factors. ${ }^{33}$ Due to the introduction of new treatment modalities, more current analyses of large databases might be needed to readdress this issue. Nonetheless, our material, as well as the study by Johnson et al, show a survival advantage for women in both early and late time periods analysed, indicating that the effect of sex on survival might be independent of current advances in treatment regimens.

\section{Stage}

Several retrospective studies have reported recent changes in stage distribution for non-small cell lung cancer (NSCLC), with an increasing proportion of stage IV NSCLC after the year $2000 .{ }^{34}{ }^{35}$ This trend has mostly been attributed to the increased use of fluorodeoxyglucose (FDG)-positron emission tomography (PET) and MRI of the brain. Although the CRN uses a condensed staging system, only $1-2 \%$ of all cases are of unknown stage, thereby allowing an accurate assessment of staging proportions. We observed a shift from earlier to more advanced disease from 1993 to 2004. Since 2004 the fraction of local stage lung cancer has increased in both sexes, most predominantly in women, as seen by others. ${ }^{6}$ MRI for diagnosis of cerebral lesions in patients with lung cancer has only been in more widespread use in recent years, and the introduction of FDG-PET only came into practical use in Norway after 2006. It is therefore unlikely that the changing proportion of stages is due to stage migration, and it remains to be seen if this positive development continues.

Our complete database allows assessment of RR of death by sex stratified by all stages of disease. We found a statistically significant survival advantage in favour of women independent of stage in multivariate analyses. Visbal et al also showed that men with stage III and IV disease were at significantly increased risk of mortality compared with women. ${ }^{4}$ More recent registry studies have not examined the effect of sex on survival in advanced stages of disease. ${ }^{2} 26$ However, others have documented that women live longer than men given the same treatment, in both early and late stage disease. ${ }^{810} 2636$

One might expect that the effect of sex on survival data obtained over a long time period might be confounded by changes in treatment algorithms. We did not adjust for treatment in our analyses, as such information in large, national registries is often missing or inaccurate ${ }^{37}$ Certain differences in the treatment of men and women have been highlighted in previous studies; a higher fraction of lobectomies ${ }^{38} 39$ and smaller radiation doses in women, ${ }^{38}$ yet others did not observe any differences in treatment approaches. ${ }^{40}$ In addition, a study that included treatment as a potential confounder in a multivariate model reported no difference in sex effect on survival. ${ }^{4}$

In conclusion, it is evident that further studies need to be undertaken to delineate biological differences in lung cancer between sexes. Emerging evidence of such differences 
emphasises the importance of continuous research, and should encourage collaborative interdisciplinary studies where large data sets and biospecimens are easily available and well defined in terms of epidemiological, clinical and molecular characteristics. Our findings in this large, population-based study show that adenocarcinoma is currently the most frequent histological subgroup in both sexes, and women are diagnosed at an earlier stage and age than men. We observe increasing short- and longterm survival among both sexes, and show through multivariate analysis that women have better survival than men, irrespective of stage, age, period of diagnosis and among specific histological subgroups, most evident in women with adenocarcinoma. Our results indicate that the effect of sex on lung cancer survival should be prospectively considered in future trial designs.

Funding Norwegian Research Council/Forskingsrådet.

Competing interests None.

Ethics approval This study was conducted with the approval of the Regional committee for medical and health related research ethics (REK), South East Norway.

Provenance and peer review Not commissioned; externally peer reviewed.

\section{REFERENCES}

1. American Cancer Society. Global Cancer Facts \& Figures. Atlanta, GA: American Cancer Society, 2007.

2. Freedman ND, Leitzmann MF, Hollenbeck AR, et al. Cigarette smoking and subsequent risk of lung cancer in men and women: analysis of a prospective cohort study. Lancet Oncol 2008:9:649-56.

3. Radzikowska E, Glaz P, Roszkowski K. Lung cancer in women: age, smoking, histology, performance status, stage, initial treatment and survival. Population-based study of 20561 cases. Ann Oncol 2002;13:1087-93.

4. Visbal AL, Williams BA, Nichols FC 3rd, et al. Gender differences in non-small-cell lung cancer survival: an analysis of 4,618 patients diagnosed between 1997 and 2002. Ann Thorac Surg 2004;78:209-15; discussion 15

5. Levi F, Franceschi S, La Vecchia C, et al. Lung carcinoma trends by histologic type in Vaud and Neuchatel, Switzerland, 1974-1994. Cancer 1997;79:906-14.

6. Bilello KS, Murin S, Matthay RA. Epidemiology, etiology, and prevention of lung cancer. Clin Chest Med 2002;23:1-25.

7. Hsu LH, Chu NM, Liu CC, et al. Sex-associated differences in non-small cell lung cancer in the new era: is gender an independent prognostic factor? Lung Cancer 2009:66:262-7.

8. Wakelee HA, Wang W, Schiller JH, et al. Survival differences by sex for patients with advanced non-small cell lung cancer on Eastern Cooperative Oncology Group trial 1594. J Thorac Oncol 2006:1:441-6.

9. Schiller JH, Harrington D, Belani CP, et al. Comparison of four chemotherapy regimens for advanced non-small-cell lung cancer. N Engl J Med 2002;346:92-8.

10. Ferguson MK, Wang J, Hoffman PC, et al. Sex-associated differences in survival of patients undergoing resection for lung cancer. Ann Thorac Surg 2000;69:245-9; discussion 9-50.

11. Chang JW, Asamura H, Kawachi R, et al. Gender difference in survival of resected non-small cell lung cancer: histology-related phenomenon? J Thorac Cardiovasc Surg 2009:137:807-12

12. Alexiou C, Onyeaka CV, Beggs D, et al. Do women live longer following lung resection for carcinoma? Eur J Cardiothorac Surg 2002;21:319-25.

13. Larsen IK, Smastuen M, Johannesen TB, et al. Data quality at the Cancer Registry of Norway: an overview of comparability, completeness, validity and timeliness. Eur J Cancer 2009;45:1218-31.

14. American Cancer Society. Manual of Tumor Nomenclature and Coding. New York, NY: American Cancer Society, 1968.
15. Percy C, Van Holten V, Muir C, eds. International Classification of Diseases for Oncology. 2nd edn. Geneva: World Health Organization, 1990.

16. Doll R, Payne P, Waterhouse J, eds. Cancer Incidence in Five Continents: A Technical Report. Berlin: Springer-Verlag (for UICC), 1966.

17. Hakulinen T. Cancer survival corrected for heterogeneity in patient withdrawal. Biometrics 1982;38:933-42.

18. Devesa SS, Bray F, Vizcaino AP, et al. International lung cancer trends by histologic type: male:female differences diminishing and adenocarcinoma rates rising. Int $J$ Cancer 2005;117:294-9.

19. Youlden DR, Cramb SM, Baade PD. The international epidemiology of lung cancer: geographical distribution and secular trends. J Thorac Oncol 2008;3:819-31.

20. Bain C, Feskanich D, Speizer FE, et al. Lung cancer rates in men and women with comparable histories of smoking. J Natl Cancer Inst 2004;96:826-34.

21. Lund $\mathbf{K E}$, Lund M, Bryhni A. [Tobacco consumption among men and women 1927-2007] (in Norwegian). Tidsskr Nor Laegeforen 2009:129:1871-4.

22. Holmberg L, Sandin F, Bray F, et al. National comparisons of lung cancer survival in England, Norway and Sweden 2001-2004: differences occur early in follow-up. Thorax 2010;65:436-41.

23. von Plessen C, Strand TE, Wentzel-Larsen T, et al. Effectiveness of third-generation chemotherapy on the survival of patients with advanced non-small cell lung cancer in Norway: a national study. Thorax 2008;63:866-71.

24. Khuder SA. Effect of cigarette smoking on major histological types of lung cancer: a meta-analysis. Lung Cancer 2001:31:139-48.

25. Jackman DM, Johnson BE. Small-cell lung cancer. Lancet 2005;366:1385-96.

26. Sakurai H, Asamura H, Goya T, et al. Survival differences by gender for resected non-small cell lung cancer: a retrospective analysis of 12,509 cases in a Japanese Lung Cancer Registry study. J Thorac Oncol 2010;5:1594-601.

27. Nordquist LT, Simon GR, Cantor A, et al. Improved survival in never-smokers vs current smokers with primary adenocarcinoma of the lung. Chest 2004;126:347-51.

28. Tsao AS, Liu D, Lee JJ, et al. Smoking affects treatment outcome in patients with advanced nonsmall cell lung cancer. Cancer 2006;106:2428-36.

29. Tammemagi CM, Neslund-Dudas C, Simoff M, et al. Smoking and lung cancer survival: the role of comorbidity and treatment. Chest 2004;125:27-37.

30. Toyooka S, Takano T, Kosaka T, et al. Epidermal growth factor receptor mutation, but not sex and smoking, is independently associated with favorable prognosis of gefitinib-treated patients with lung adenocarcinoma. Cancer Sci 2008;99:303-8.

31. Janssen-Heijnen ML, Schipper RM, Klinkhamer PJ, et al. Improvement and plateau in survival of small-cell lung cancer since 1975: a population-based study. Ann Oncol 1998:9:543-7.

32. Osterlind $\mathbf{K}$, Andersen PK. Prognostic factors in small cell lung cancer: multivariate model based on 778 patients treated with chemotherapy with or without irradiation. Cancer Res 1986;46:4189-94.

33. Johnson BE, Steinberg SM, Phelps R, et al. Female patients with small cell lung cancer live longer than male patients. Am J Med 1988:85:194-6.

34. Chee KG, Nguyen DV, Brown M, et al. Positron emission tomography and improved survival in patients with lung cancer: the Will Rogers phenomenon revisited. Arch Intern Med 2008;168:1541-9.

35. Morgensztern D, Goodgame B, Baggstrom MQ, et al. The effect of FDG-PET on the stage distribution of non-small cell lung cancer. J Thorac Oncol 2008;3:135-9.

36. Pirker R, Pereira JR, Szczesna A, et al. Cetuximab plus chemotherapy in patients with advanced non-small-cell lung cancer (FLEX): an open-label randomised phase II trial. Lancet 2009:373:1525-31.

37. Rostad H, Strand TE, Langmark FY, et al. [Lung cancer without metastases-are al patients with resectable tumor operated?] (in Norwegian). Tidsskr Nor Laegeforen 2008:128:920-3

38. Foegle J, Hedelin G, Lebitasy MP, et al. Specific features of non-small cell lung cancer in women: a retrospective study of 1738 cases diagnosed in Bas-Rhin between 1982 and 1997. J Thorac Oncol 2007:2:466-74.

39. de Perrot M, Licker M, Bouchardy $\mathrm{C}$, et al. Sex differences in presentation, management, and prognosis of patients with non-small cell lung carcinoma. J Thorac Cardiovasc Surg 2000;119:21-6.

40. Mahmud SM, Reilly M, Comber H. Patterns of initial management of lung cancer in the Republic of Ireland: a population-based observational study. Lung Cancer 2003;41:57-64. 